UDC 340.122

LBC 87.66

\title{
THE IDEA OF PHRONESIS IN HERMENEUTICAL PHILOSOPHY OF LAW
}

\author{
Natalia I. Satokhina \\ Yaroslav Mudryi National Law University, Kharkov, Ukraine
}

\begin{abstract}
Introduction: the article is devoted to the reactualization of the Aristotelian ideas of phronesis in hermeneutic philosophy to clarify the nature of jurisprudence as an experience of law. Results: in the light of the typology of experience and knowledge forms proposed by Aristotle (episteme, techne, phronesis) the question of whether jurisprudence is a science in the strong sense of the word, or just a technology, gets a new interpretation. The problem is placed in a broad historical and philosophical context. In particular, the idea of phenomenological hermeneutics (Husserl, M. Heidegger, H.-G. Gadamer) as an antimetaphysical project aimed at the criticism of natural scientific rationality and the rehabilitation of phronesis experience of understanding is clarified. However, the experience of law is conceived as a paradigmatical example of phronesis, which, in contrast to the experience of art (techne) and the experience of science (episteme), suggests rather than removing the existing legal meanings from the authoritative sources for their subsequent application to a given situation, and the involuntary creation of these meanings, but their reproduction in the dialogue with tradition, whose part we are. So there reveals the rhetorical nature of all the reasoning about law as a conversation, where participants strive not to defend their position not to accept the position of the interlocutor, but to understand the essence of the case in question. Conclusions: in this sense, hermeneutical philosophy of law is an alternative to both dogmatism and relativism in jurisprudence, putting in place of the metaphysical beliefs about the existence of independent moral truths the experience of our own historicity.
\end{abstract}

Key words: Aristotle, phronesis, hermeneutic philosophy of law, experience, understanding, jurisprudence.

УДК 340.122

ББК 87.66

\section{ИДЕЯ ФРОНЕЗИСА В ГЕРМЕНЕВТИЧЕСКОЙ ФИЛОСОФИИ ПРАВА Наталья Ивановна Сатохина}

Национальный юридический университет им. Ярослава Мудрого, г. Харьков, Украина

Введение: статья посвящена реактуализации аристотелевской идеи фронезиса в рамках герменевтической философии с целью прояснения природы юриспруденции как опыта права. Результаты: в свете предложенной Аристотелем типологии форм опыта и знания (эпистеме, технэ, фронезис) вопрос о том, является ли юриспруденция наукой в срогом смысле этого слова или всего лишь технологией, получает новое прочтение. Проблема помещается в широкий историко-философский контекст. В частности, проясняется идея феноменологической герменевтики (Э. Гуссерль, М. Хайдеггер, Х.-Г. Гадамер) как антиметафизического проекта, направленного на критику естественнонаучной рациональности и реабилитацию фронетического опыта понимания. При этом опыт права мыслится как парадигматический пример фронезиса, который, в отличие от опыта искусства (технэ) и опыта науки (эпистеме), предполагает скорее не извлечение существующих правовых смыслов из авторитетных источников с целью их последующего применения к той или иной ситуации, но и непроизвольное создание этих смыслов, их воспроизведение в диалоге с традицией, частью которой мы являемся. Так раскрывается риторическая природа всякого рассуждения о праве как разговора, участники которого стремятся не отстоять свою позицию и не принять позицию собеседника, а понять суть самого дела, о котором идет речь. Выводы: в этом смысле герменевтическая философия права оказывается альтернативой как догматизму, так и релятивизму в юриспруденции, поставив на место метафизических представлений о существовании независимых моральных истин опыт нашей собственной историчности.

Ключевые слова: Аристотель, фронезис, герменевтическая философия права, опыт, понимание, юриспруденция. 


\section{Введение}

Jus est ars boni et aequi, - говорит Ульпиан, открывая пространство для многочисленных интерпретаций. Ведь невозможно сказать, что такое юриспруденция, не определив сначала, что мы понимаем под «добром» и «справедливостью». Собственно, различные толкования boni и aequi и были положены в основу тех или иных представлений о природе права. В то же время спектр возможных переводов латинского слова ars долгое время оставался вне поля зрения юристов, хотя именно тут и кроется подлинная проблема: каким образом человек причастен к «добру» и «справедливости», или какова природа правового опыта?

\section{Аристотелевские различия}

В книге VI «Никомаховой этики» Аристотель выделяет три типа знания, соответствующие трем формам человеческого опы-

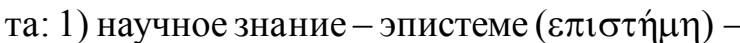
выражается в теории и касается вещей неизменных, например, законов природы; 2) знание в сфере творчества - технэ ( $\tau \dot{\varepsilon} \chi \nu \eta)$ - применяется в искусстве и представляет собой мастерство, технологию, умение создавать что-то новое; 3) практическое знание - фро-

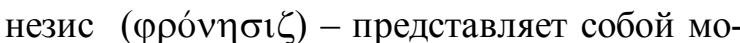
рально-практическую мудрость относительно правильных действий в конкретной ситуации. Его нельзя получить теоретически, оно приобретается с опытом. В отличии от эпистеме (знания «почему»), технэ и фронезис касаются вещей конкретных и изменчивых, при этом технэ (знание «как») - это сфера производства, тогда как фронезис - сфера действия [2, с. 173-218]. К какому же из этих типов знания следует отнести знание о праве? Так, если Г. Кельзен рассматривает правоведение как теорию позитивного права, или науку о позитивном праве [5, с. 11], то П. Амселек настаивает на том, что в строгом смысле слова наука о праве невозможна, а правоведы, поглощенные мыслями о ноу-хау, занимаются на самом деле преимущественно технологией как теорией юридической техники [1]. В свою очередь, датский исследователь Б. Фливберг констатирует крах всех общественных наук и утверждает, что их реабилитация сегодня возможна только в качестве наук фронетических (направленных на контекстуальное обсуждение ценностей и норм), которые он противопоставляет наукам эпистемологическим (построенным по аналогии с естественными науками). В отличие от эпистеме, фронетическое знание предполагает диалог исследователя со своим «объектом» и, таким образом, ставит под сомнение традиционные представления о беспристрастности, объективности и истине [10, p. 1-37].

\section{Фронезис как герменевтический опыт}

Реактуализация идеи фронезиса в современной мысли отражает основные тенденции, характерные для неклассической философии в целом. Так, если философия Нового времени была ориентирована на науку как единственный способ познания, претендующий на истину, то философия неклассическая, скорее, исходит из того, что опыт никогда не исчерпывается теорией, и, соответственно, постижение истины превышает область, контролируемую научной методикой. В противовес гносеологизму Нового времени, сводящему всякое освоение мира к научному познанию, лейтмотивом неклассической философии становится реабилитация повседневного опыта.

Одним из философских направлений, инспирированных этим мотивом, стала философская герменевтика, центральной проблемой которой является феномен понимания как фронетического опыта. Так, М. Хайдеггер в «Бытии и времени» определяет герменевтику как «феноменологию Dasein», где Dasein - это сущее, которое отличается от иного сущего осмысленным отношением к себе и к миру. Понимание, таким образом, оказывается фундаментальным способом бытия Dasein в мире. Иными словами, речь идет о том, что уже в факте существования содержится понимание и что существование как таковое является интерпретирующим, проясняющим себя. Поэтому философию как таковую Хайдеггер называет «герменевтикой фактичности» $[8$, с. 12, 142-148]. При этом философ утверждает, что современное разделение теории, практики и искусства игнорирует их изначальную укорененность в единой основе. 
Именно во фронезисе Хайдеггер усматривает не только наиболее подлинный способ обхождения с миром и модель собственной идеи философии как герменевтической феноменологии, но и ту изначальную основу опыта, которая впоследствии дифференцируется и поддается забвению, что, в свою очередь, приводит к приоритету познавательной модели теории в западноевропейской традиции $[9$, с. 130 и далее].

Идеи Хайдеггера получили развитие в творчестве Х.-Г. Гадамера. В своем таgnuториs «Истина и метод» он противопоставляет формальному разуму и научному опыту мира («методу») морально-практическую мудрость и опыт герменевтического постижения «истины». В противовес монологу выработанного Новым временем «метода» герменевтическое понимание представляет собой опыт диалога, восходящий к античной риторической традиции.

В отличие от радикального сомнения Декарта, точкой отсчета в процессе герменевтического понимания является предпонимание, обусловленное традицией, что, однако, не ограничивает свободу понимания, а, напротив, только и делает ее возможной. Более того, тот, кто «мнит себя свободным от предрассудков, тот испытывает на себе могущество этих предрассудков, господствующих над ним без всякого контроля с его стороны» [3, с. 424]. Являясь частью той или иной традиции, мы никогда не можем полностью противопоставить себя ей, поскольку так или иначе всегда говорим от ее имени. Вместе с тем ответы на вопросы, поставленные современностью, сами становятся частью предания, которое в своем обновленном виде определяет предпонимание последующих интерпретаторов. При этом речь идет не о слепом подчинении авторитету традиции, а, скорее, о диалоге с последней, изменяющем обоих его участников [3, c. 317-363, 409-426].

Таким образом, герменевтическая философия отходит от чистого, не связанного с бытием знания: мы не стоим перед фактами, которые только устанавливаем, но непосредственно затронуты тем, что познаеми на что направлено наше действие. Этим и определяется главное отличие эпистеме от фронезиса. Однако фронезис отличается также и от тех- нэ - умения создавать определенные вещи. Вопрос о том, что справедливо, а что нет, не может быть решен в отрыве от ситуации, тогда как идея того, что хочет изготовить ремесленник, определена заранее. Именно здесь Гадамер видит подлинную проблему юридической герменевтики: образцы поведения не являються вечными и неизменными, но и не являються простыми конвенциями, отражая природу вещей, и дело лишь в том, что эта последняя определяет себя всякий раз только в применении. К тому же если технэ можно овладеть в совершенстве и таким образом исключить необходимость самостоятельного обдумывания, то фронезис в состоянии идеальной завершенности является совершенством способности суждения и принятия решений. Наконец, фронезис всегда предполагает, что речь идет не только обо мне, но и о ком-то другом, связанном со мной общностью устремлений [3, с. 375-382].

Для прояснения риторической природы всякого опыта понимания Гадамер использует пример обычного разговора между двумя людьми, участники которого стремятся не отстоять свою позицию и не принять позицию собеседника, а понять суть самого дела, о котором идет речь: «Разговор есть процесс взаимопонимания. Поэтому во всяком подлинном разговоре мы вникаем в слова другого, действительно считаемся с его точкой зрения и ставим себя на его место: не с тем, однако, чтобы понять его самого как данную личность, но с тем, чтобы понять, что он говорит» [3, с. 448]. При этом герменевтическая ситуация, в которой мы находимся по отношению к тексту, подобна той, в которой находятся два участника устной беседы. В подобном ключе П. Слотердайк различает два типа отношения исследователя к «объекту». В первом случае речь идет о позиции дистанцирования и овладения последним. Здесь мы наблюдаем примат метода над предметом исследования, или примат познающего над познаваемым. Результатом такого превосходства становится представление о том, что все настоящие науки в конце концов будут иметь по поводу одной проблемы только одну правильную теорию. Там же, где существует несколько гипотез, выдает себя слабость субъекта, которая дает вещам шанс показать 
себя в их многозначности: «чем слабее наши методы, тем лучше для “вещей”». В свою очередь, признание приоритета объекта означало бы признание над собой какой-то власти. А поскольку мы отождествляем все, что выше с нас, с источником подавления и угнетения, то такая позиция автоматически отбрасывается. Однако, по мнению Слотердайка, существует и приоритет иного рода, основанный не на подчинении, а на любви и наслаждении от понимания «объекта», приоритет, который только и способен обеспечить подлинное взаимопонимание: «Способность отдавать приоритет объекту была бы равнозначна способности жить и давать жить другим (а не “жить и давать умереть другим”)» [7, c. 537-542].

Таким образом, речь идет о необходимости признать другого (будь то другой человек как собеседник, историческое предание или текст как «объект» понимания) в его притязании на то, чтобы быть услышанным. А это требует принципиальной открытости различным ответам на поставленный вопрос и готовности к опыту как готовности пересмотреть свои убеждения, ибо «всякий опыт, достойный этого имени, идет вразрез с нашими ожиданиями» [3, с. 419]. При этом главным результатом понимания оказывается не убеждение или навык; опыт учит нас главным образом тому, чтобы оставаться открытыми для нового опыта [3, с. 409-445].

\section{Юриспруденция как фронетический опыт}

Связь между юриспруденцией и фронезисом выражена уже на уровне языка. В отличие от наиболее употребляемых синонимов («правоведение», «юридическая наука», «теория права»), которые этимологически отсылают к теоретическому опыту, слово «юриспруденция» происходит от лат. jus - «право» и prudentia - «рассудительность», «практическая мудрость». Именно как prudentia Ци-

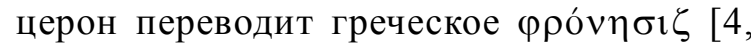
c. 527-533].

По мнению П. Рикера, высказывание права при конкретных обстоятельствах судебного процесса представляет собой парадигматический пример фронетического сужде- ния, которое, как и философствование, невозможно вне свободного мышления, как невозможна медицина без способности врача выйти за пределы стандартизированных рекомендаций и принять решение в ситуации неопределенности [6, с. 249-259]. На значение контекста для правового суждения указывает еще Аристотель, когда отмечает, что «любой закон составлен для общего случая, однако о некоторых вещах невозможно сказать правильно в общем виде» [2, с. 168]. Более радикально эту идею раскрывает финский исследователь Й. Тонтти, когда утверждает, что правовая традиция никогда не дает нам правильных ответов, а лишь спектр возможных решений, выбор между которыми с необходимостью предполагает моральное и политическое суждение. Как отмечает мыслитель, эта критическая модель призвана прежде всего способствовать постоянной самокритике правоприменителя, чтобы принимаемые им решения могли претендовать на справедливость. В этом смысле требование беспристрастности судьи означает не что иное, как требование постоянного выявления и пересмотра собственных предрассудков с точки зрения их приемлемости в контексте конкретного дела. Иначе говоря, как метафорически пишет Тонтти, только Фемида, которая, сняв повязку с глаз, пытается осознать собственные предубеждения, понимая, что на самом деле весы никогда не могут быть уравновешены, может использовать свой меч таким образом, чтобы это могло считаться оправданным [13, с. 186].

Следовательно, знание о праве не является предметным знанием, а целиком определяется применением. Однако речь идет не об отказе от теории в пользу практики, а скорее о диалоге между ними. С целью прояснения этого тезиса американский философ Ф.Дж. Мутс III сравнивает фронетический опыт правоведа с опытом психотерапевта, деятельность которого в рамках постмодернистского подхода к психотерапии является «теоретически осведомленной практикой»: он усваивает теоретические установки для того, чтобы помочь клиенту, но при этом не пытается избежать собственного участия в диалоге с последним, занимая позицию «незнания» и таким образом отказываясь от попытки управлять клиентом 
с позиции теоретического превосходства. Используя этот пример, Мутс пытается показать, что право представляет собой не понятие, которое следует прояснить, а повествовательно структурированный процесс, ориентированный не на создание идеального правового нарратива для дальнейшего применения его на практике, а на непрерывное воспроизведение правовых смыслов [11, с. 144-151].

Подобную герменевтическую точку зрения представляет судья Верховного суда США Д. Саутер, когда в своем особом мнении в деле Washington v. Glucksberg (1997) выступает против претензии суда на беспристрастное определение «фундаментальных» конституционных прав, существующих как «внетекстовые абсолютные величины». Вместо этого, по мнению Саутера, суду следовало бы сосредоточиться на обстоятельствах самого дела: мы не можем судить о каких-либо конституционных правах прежде рассмотрения доводов сторон по конкретному делу, поскольку права скорее обусловливаются обстоятельствами дела, чем дедуцируются из абстрактных принципов ( цит. по: [11, с. 319-324]). При этом речь не идет о релятивизме, в соответствии с которым всякое понимание права оправданно: даже если интерпретации одинаково хорошо обоснованы формально, одна из них все же оказывается лучше других в свете конкретных целей, то есть более приемлемой. Соответственно, наилучшая интерпретация, которая всегда контекстуальна, ни апеллирует к изначальным, трансцендентным, вечным истинам, ни переходит в интерпретационный произвол. В этом смысле норвежские исследователи Х. Бондевик и И. Бостад рассматривают герменевтику как «третий путь по ту сторону объективизма и релятивизма» в поиске ответов на современные вызовы правам человека (цит. по: [12, с. 77]).

\section{Выводы}

Таким образом, герменевтическая философия раскрывает фронетическую природу всякого рассуждения о праве как разговора, участники которого стремятся не отстоять свою позицию и не принять позицию собеседника, а приблизиться к сути самого дела. Соответственно, юриспруденция как опыт права не сводится ни к науке, ни к технологии, поскольку предполагает скорее не извлечение существующих правовых смыслов из авторитетных источников с целью их последующего применения к той или иной ситуации, но и не произвольное создание этих смыслов, а их воспроизведение в диалоге с традицией, частью которой мы являемся. В этом смысле герменевтическая философия права оказывается альтернативой как догматизму, так и релятивизму в юриспруденции. Наконец, герменевтика напоминает нам о том, что правосудие может быть только человеческим, никогда не претендуя на окончательное суждение, что блестяще выразил П. Рикер через символ отделения Дике, человеческой справедливости, от Фемиды, «последнего и мрачного прибежища приравнивания Мести к Правосудию» $[6$, c. 170].

\section{СПИСОК ЛИТЕРАТУРЫ}

1. Амселек, П. Научный статус правовых исследований / П. Амселек; пер. с фр. В. А. Токарева // Энциклопедия правоведения или интегральная юриспруденция? Проблемы изучения и преподавания. - М. : Норма, 2013. - С. 208-220.

2. Аристотель. Никомахова этика / Аристотель; пер. с древнегреч. под ред. А. И. Доватур и Ф. Х. Кессиди // Сочинения : в 4 т. / Аристотель. М. : Мысль, 1976-1984. - Т. 4, 1983. - С. 53-293.

3. Гадамер, Х.-Г. Истина и метод: Основы философской герменевтики / Х.-Г. Гадамер ; пер. с нем. под ред. Б. Н. Бессонова. - М. : Прогресс, 1988. $704 \mathrm{c}$.

4. Європейський словник філософій : Лексикон неперекладностей : пер. $з$ фр. - Киев : ДУХ І ЛІТЕРА, 2009. - Т. 1. - $576 \mathrm{c}$.

5. Кельзен, Г. Чисте Правознавство / Г. Кельзен ; пер. $з$ нім. О. Мокровольського. - К. : Юніверс, 2004. $-496 \mathrm{c}$.

6. Рикер, П. Справедливое / П. Рикер ; пер. с фр. Б. Скуратова, П. Хицкого. - М. : Гнозис : Логос, 2005. $-304 \mathrm{c}$.

7. Слотердайк, П. Критика цинического разума / П. Слотердайк ; пер. с нем. А. Перцева. - Екатеринбург : У-Фактория ; М. : АСТ МОСКВА, 2009. $800 \mathrm{c}$.

8. Хайдеггер, М. Бытие и время / М. Хайдеггер ; пер. с нем. В. В. Бибихина. - СПб. : Наука, 2006. $-452 \mathrm{c}$.

9. Хайдеггер, М. Феноменологические интерпретации Аристотеля (Экспозиция герменевтичес- 


\section{ГЛАВНАЯ ТЕМА НОМЕРА}

кой ситуации) / М. Хайдеггер ; пер. с нем. Н. А. Артеменко. - СПб. : ИЦ «Гуманитарная академия», 2012. -224 c.

10. Flyvbjerg, B. Making Social Science Matter: Why Social Inquiry Fails and How It Can Succeed Again / B. Flyvbjerg. - Cambridge University Press, 2001. -212 p.

11. Mootz, F.-J. III. Law, Hermeneutics and Rhetoric / F.-J. III Mootz. - Ashgate, 2010. - 470 p.

12. Research Methods in Human Rights: A Handbook / B. A. Andreassen, H.-O. Sano, S. McInerney-Lankford, ed. - Cheltenham, UK ; Northampton, USA : Edward Elgar Publishing, 2017.$480 \mathrm{p}$.

13. Tontti, J. Right and Prejudice: Prolegomena to a Hermeneutical Philosophy of Law / J. Tontti. Aldershot : Ashgate, 2004.-204 p.

\section{REFERENCES}

1. Amselek P. Nauchnyy status pravovykh issledovaniy [Scientific Status of Legal Research]. Entsiklopediya pravovedeniya ili integralnaya yurisprudentsiya? Problemy izucheniya $i$ prepodavaniya [Encyclopedia of Law or the Integral Jurisprudence? Problems of Studying and Teaching]. Moscow, Norma Publ., 2013, pp. 208-220.

2. Aristotle. Nikomakhova etika [Nicomachean Ethics]. Sochineniya: v 4-kht. [Works in 4 vols. Vol. 4]. Moscow, Mysl Publ., 1983, pp. 53-293.

3. Gadamer H.-G. Istina i metod: Osnovy filosofskoy germenevtiki [Truth and Method: Basics of Philosophical Hermeneutics]. Moscow, Progress Publ., 1988. 704 p.

4. Evropeyskiy slovnik filosofiy: Leksikon neperekladnostey [European Dictionary of Philosophies. Lexicon of Untranslatable]. Kyiv, DUH I LITERA, 2009, vol. 1. 576 p. (in Ukrainian).

5. Kelsen G. Chiste Pravoznavstvo [Pure Theory of Law]. Kyiv, Yuunivers Publ., 2004. 496 p.

6. Ricoeur P. Spravedlivoe [The Fair]. Moscow, Gnozis Publ.; Logos Publ., 2005. 304 p.

7. Sloterdijk P. Kritika tsinicheskogo razuma [Critique of Cynical Reason]. Ekaterinburg, U-Faktoriya Publ.; Moscow, AST MOSKVA Publ., 2009. 800 p.

8. Heidegger M. Bytie $i$ vremya [Being and Time]. Saint Petersburg, Nauka Publ., 2006. 452 p.

9. Heidegger M. Fenomenologicheskie interpretatsii Aristotelya (Ekspozitsiya germenevticheskoy situatsii) [Phenomenological Interpretations of Aristotle (Initiation into Phenomenological Research)]. Saint Petersburg, Gumanitarnaya akademiya Publ., 2012. 224 p.

10. Flyvbjerg B. Making Social Science Matter: Why Social Inquiry Fails and How It Can Succeed Again. Cambridge, Cambridge University Press, 2001. 212 p.

11. Mootz F.-J. Law, Hermeneutics and Rhetoric. Aldershot, Ashgate, 2010. 470 p.

12. Andreassen B.A., Sano H.-O., McInerneyLankford S., eds. Research Methods in Human Rights: A Handbook. Cheltenham, UK; Northampton, USA, Edward Elgar Publishing, 2017.480 p.

13. Tontti J. Right and Prejudice: Prolegomena to a Hermeneutical Philosophy of Law. Aldershot, Ashgate, 2004. 204 p.

\section{Information about the Author}

Natalia I. Satokhina, Candidate of Juridical Sciences, Assistant Professor, Department of Philosophy, Yaroslav Mudryi National Law University, Pushkinskaya St., 77, 61024 Kharkov, Ukraine, nataliasatokhina@gmail.com.

\section{Информация об авторе}

Наталья Ивановна Сатохина, кандидат юридических наук, ассистент кафедры философии, Национальный юридический университет им. Ярослава Мудрого, ул. Пушкинская, 77, 61024 г. Харьков, Украина, nataliasatokhina@gmail.com. 